\title{
'CELESTINA' Y EL LENGUAJE DEL CUERPO
}

\author{
M. Concepción Bados-Ciria \\ University of Washington
}

\begin{abstract}
LUCR-Así que continuo se te caían, como de entre las manos, señales muy claras de pena (...) cumple a los servidores obedecer con diligencia corporal y no con artificiales consejos de lengua.
\end{abstract}

(Celestinn X, 161)

La estrecha relación existente entre el lenguaje verbal y el que se desprende de los gestos, posturas y señales emitidos por el cuerpo físico ha sido objeto de estudio desde los inicios de la historia del pensamiento occidental. Los primeros escritos en este campo se referían al lenguaje corporal de hablantes profesionales como los oradores públicos y los actores. Antiguos tratados de retórica como De Oratore de Cicerón o Institutio Oratoria, de Quintiliano, advertían sobre la eficacia y la necesidad de coordinación entre indicios corporales y lenguaje verbal a la hora de expresarse en público. Estos textos, aparecidos en el siglo primero antes de Cristo, no sólo presentaban aspectos prácticos y perspectivas teóricas en relación con el uso de los gestos como apoyo del lenguaje verbal, sino que también, promovieron las bases en las que se asienta parte de los estudios psicológicos contemporáneos.

En este trabajo realizo un estudio de Celestina de acuerdo a las propuestas de Pierre Feyereisen y Jacques Dominique de Lannoy, quienes en su obra Gestures and Speech: Psychological Investigations acuerdan la identificación entre gestos y lenguaje de modo que proponen un 
"lenguaje corporal," cuyos efectos residen, principalmente, en realzar la expresión de las pasiones y los sentimientos humanos más íntimos. A este respecto recogen una afirmación de Quintiliano que enfatiza la similitud entre gestos y lenguaje: "For other portions of the body merely help the speaker, whereas the hands may almost be said to speak. Do we not use them to demand, promise, summon, dismiss, threaten, supplicate, exppress aversion or fear, question or deny?" (Gestures 1). Coincidimos con esta declaración ya que de ella deriva la comunicación deseada en todo texto literario, y más en el que nos ocupa, Celestina, por tratarse de una obra concebida para ser leída entre grupos de amigos en círculo cerrado $y$, tal vez, público.

La "comedia o tragicomedia de Calisto y Melibea, compuesta en reprehensión de los locos enamorados, que, vencidos en su desordenado apetito, a sus amigas llaman y dicen ser su dios"1 ve la luz como obra escrita en 1499. A esta "primitiva" comedia le siguen diversas ediciones que enmarcan las distintas evoluciones de la obra de Rojas hasta su edición más definitiva, la de Valencia en 1514 (31-32). En cualquier caso, el diálogo que se establece entre lector y texto y, más aún, el que se produce entre los distintos personajes representados en aquél es uno de los artificios retóricos que hace de esta obra un caso excepcional en la literatura de la época.

Desde un principio Rojas exige la colaboración de sus lectores y les da una de las claves más importantes para la interpretación de la obra. Al escribir "Así cuando diez personas se juntaren a oír esta comedia" (43), se sugiere ya el papel decisivo del cuerpo, tanto el del lector como el de los receptores, para una eficaz comunicación de la misma. A modo de conclusión, vuelve Rojas a interpelar al lector para animarle a contar y propagar lo leído: "No dudes ni hayas vergüenza, lector. Narrar lo lascivo, que aquí se te muestra" (237).

La participación del cuerpo en el proceso de la lectura en voz alta y ante un grupo de personas es también una de las exigencias del corrector de la obra, Alonso de Proaza. Este advierte que el lenguaje corporal, con su heterogénea proliferación de posturas y gestos, ha de ser el detonante definitivo que, combinado con el lenguaje verbal, resuelva eficazmente los propósitos persuasivos que toda obra de arte persigue en sus receptores. Escribe Proaza:

${ }^{1}$ Cito de la edición de Celestina preparada por D. S. Severin (Madrid: Alianza, 1979), p. 44. Las páginas de las citas aparecerán indicadas en el texto. 
Si amas y quieres a mucha atención

Leyendo a Calisto mover los oyentes, Cumple que sepas hablar entre dientes, A veces con gozo, esperanza y pasión, A veces airado con gran turbación.

Finge leyendo mil artes y modos, Pregunta y responde por boca de todos, llorando y riendo en tiempo y sazón. (238)

La inscripción del cuerpo como fenómeno de percepción llega hasta los receptores por expresa intención de Rojas, quien se nos presenta "asaz veces retraído en mi cámara, acostado sobre mi propia mano, echando mis sentidos por ventores y mi juicio a volar" (35) para indicarnos la doble importancia del cuerpo cuando se trata de comunicar con los otros. Por un lado, éste emite palabras e inscribe signos en la página, pero por otro lado la postura, la expresión no verbal es otra manera de llegar al otro, de alcanzarlo. En suma, posibilita una comunicación sincera y eficaz entre el autor y nosotros, sus receptores. Contamos con un cuerpo que nos delata y al mismo tiempo nos identifica con nuestros semejantes. Por ello, somos capaces de dar significado al lenguaje corporal de las "vidas" en "proceso" en Celestina.

No cabe duda de que los cuerpos humanos tienen dimensiones psicológicas y neurofisiológicas irreducibles y cuyas relaciones entre sí todavía son desconocidas, sin embargo hay que reconocer que esos mismos cuerpos tienen la maravillosa habilidad de proporcionar fragmentaciones, fracturas, dislocaciones que los proyectan y dirigen hacia otros cuerpos con el fin de establecer los más diversos tipos de comunicación entre ellos. Siguiendo en esta línea, el lector de Celestina destaca la constante textualización de muecas y signos externos que se manifiestan en el cuerpo perceptivo de los distintos personajes de la obra. "¿Qúe cara te mostró al principio?" (107) pregunta Calisto a Celestina para saber cómo fue recibida ésta por Melibea. Antpe la respuesta de la vieja vuelve a inquirir "¿Y a ésas llamas señales de salud?" (108), para - terminar concluyendo "pues todo eso más es señal de odio que de amor" (108). Calisto interpreta, ve a través de las palabras de Celestina el rostro de Melibea, y se muestra apenado. Más tarde al cerciorarse de que "el proceso" anda por buen camino, él mismo declara "Ya me reposa el corazón, ya descansa mi pensamiento, ya reciben las venas y recobran su perdida sangre, ya he perdido temor y tengo alegria. Subamos..." (109). Los receptores del texto vemos a Calisto saltando de gozo y arrodillándose ante Celestina. 
Junto con la aproximación psicológica surge en los años cincuenta la homóloga fenomenológica para proponer el cuerpo físico como superficie capacitada para inscribir mensajes y textos. La metáfora del cuerpo textualizado es una de las favoritas del teórico de la fenomenología, Maurice Merleau-Ponty, quien asegura que el gesto revela tanto significado como las palabras y, además, se caracteriza por ser legible. Dice Merleau-Ponty "Je ne perçois pas la colère ou la ménace comme un fait psychique caché derrière le geste, je lis la colère dans le geste, le geste ne fait pas penser à la colere, il est la colère elle-même" (Phénomenologie 215). La lectura de los gestos y mohínes adscritos a los distintos personajes por la mano de Rojas ha de llevarse a cabo del modo que nos sugiere Proaza: gesticulando e interpretando, es decir, emitiendo palabras y signos. Con todo ello llegamos a corroborar lo que Rojas hace explícito: Celestina es un texto eminentemente perceptivo, ya que la vista, el tacto, el oído de los receptores están constantemente en acción acompañando a los personajes. Estos supuestos nos llevan a coincidir con Stephen Gilman cuando afirma que el carácter oral de la obra es uno de sus rasgos más distintivos. No hace sino confirmarla como un texto objeto de percepciones múltiples.

Gilman es el gran descubridor para el mundo "celestinesco" de la oralidad de la obra de Fernando de Rojas, y así señala que "apunta al oído y al corazón, es decir, los dos blancos sucesivos del lenguaje oral" (Gilman 315). Relaciona esta decisiva característica interna de la obra con otra de signo externo: la de su presentación en veintiún actos de ininterrumpido diálogo. El diálogo como instrumento de comunicación es la clave en la que centramos nuestro estudio sobre el lenguaje del cuerpo en Celestina. Los signos externos de gozo, ira, turbación y pasión que Alonso de Proaza exige de los lectores para impresionar y agradar a sus oyentes, no son sino eco y prolongación de los expresados por los protagonistas de "carne y hueso" de la obra en su continuo dialogar por el espacio literario. En nuestra opinión, el lenguaje de sus cuerpos es tan decisivo como el verbal que se emite por sus bocas, y apunta hacia dos objetivos principales: en primer lugar a la manipulación del receptor por parte del emisor a lo largo de las conversaciones que se establecen entre los personajes. El máximo exponente de tal manipulación es Celestina dialogando con Calisto, Pármeno, Melibea y Areúsa. En segundo lugar, las señales emitidas por el cuerpo de los protagonistas delatan su verdadera intencionalidad, sus más íntimos deseos y pensamientos, muchas veces encubiertos y simulados tras su lenguaje verbal.

Según Feyereisen y De Lannoy, "An essential feature of conversation is the active participation of both partners. Among other contributions, the listener is responsible for the smooth unfolding of the 
discourse by displaying attention. To be sure to be understood, the speaker most likely relies on nonverbal and particularly facial signals sent by the listener. Receptivity may be expressed nonverbally by bodily attitudes and gaze orientation" (Gestures 19).

De este modo, el lenguaje no verbal además de enviar y recibir mensajes, puede ser utilizado para romper las defensas del interlocutor y así confirmar los poderes discursivos del emisor. Celestina, nuestra protagonista, se sirve de la acción de sus manos, de sus pies, de sus miradas, de sus ropas para afirmarse como el único y verdadero motor de la obra. En la manipulación de todos los personajes que entran en contacto conversacional con Celestina, juega un papel primordial el lenguaje de su cuerpo. Sus manos tocan a sus interlocutores físicamente al tiempo de hablarles. En ese contacto físico encontramos la más pura forma de persuasión celestinesca. Antes de ir a casa de Melibea por primera vez, la alcahueta le comenta a Pármeno " $Y$ con esto que sé cierto, voy más consolada a casa de Melibea que si la tuviese en la mano" (III, 83). Un poco antes había estado señalado la importancia de las manos y del tacto en la empresa que se propone al afirmar que "No hay cirujano que a la primera cura juzgue la herida" (III, 82). Al igual que el médico Celestina tiene que tocar y palpar a Melibea con sus manos para diagnosticarla.

Tener en sus manos a todos los que la rodean es uno de los más ardientes deseos de la que es definida por Sempronio como "vieja barbuda, hechicera, astuta, sagaz en cuantas maldades hay" (I, 56). El lector ve el cordón de Melibea en las manos de Celestina después de su primera entrevista " $\mathrm{A} A y$ cordón, cordón! Yo te haré traer por fuerza, si vivo, a la que no quiso darme su buena habla de grado!" (V, 103). La imagina estrujando y apretando el cordón símbolo del cuerpo de Melibea entre sus manos. Vemos en sus gestos desens de manifestar su poder sobre la que se ha atrevido a contradecirla en un momento: "dióse en la frente una gran palmada, como cosa de grande espanto hobiese oído, diciendo que cesase mi habla y me quitase delante" (VI, 111).

Las tretas de Celestina logran "tocar" por fin a Melibea y consiguen romper su resistencia. Al relatar a Calisto su encuentro, la vieja le dice que Melibea se halla herida "de aquella dorada frecha, que del sonido de tu nombre le tocó" (VI, 111), y ella misma se confiesa triunfadora al compararse con la abeja "a la cual los discretos deben imitar, es que todas las cosas por ella tocadas convierte en mejor de lo que son. De esta manera me ha habido con las zahareñas razones y esquivas de Melibea" (VI, 108). Su capacidad de persuasión es tal, que Calisto no duda en entregársele y así dice "Agora doy por bienempleada 
mi muerte, puesta en tales manos" (VI, 112), al tiempo que se contagia del afán celestinesco de tocar a Melibea:

CEL.- Qué la has tocado, ¿dices? Mucho me espantas.

CAL.- Entre sueños, digo (VI, 114).

Del mismo modo que Celestina fantasea con Melibea "en sus manos" antes de visitarla, también Calisto la imagina entre las suyas. En este caso, apreciamos en su frenético apretar el cordón la expresión de los deseos sexuales del enamorado que ansía encontrarse con el cuerpo de la amada. Celestina así lo advierte y le dice "Cesa ya, señor, ese devanear, que me tienes cansada de escucharte, y al cordón roto de tratarlo" (VI, 115). El maravilloso mundo del tacto hace descubrir las más íntimas emociones de Calisto ante Celestina "!Oh mis manos, con qué atrevimiento, con cuán poco acatamiento tenéis y tratáis la triaca de mi llaga!" (VI, 116). Al igual que aquí, las manos de Calisto también parecen hablar por sí solas en el último encuentro de los enamorados en el huerto de Melibea, cuando ésta finge recriminarle duramente su osado comportamiento:

¿cómo mandas a mi lengua hablar y no a tus manos que estén quedas? ¿Porqué no olvidas estas mañas? Mándalas estar sosegadas y dejar su enojoso uso y conversación insoportable...así como me es agradable tu vista sosegada, me es enojoso tu riguroso trato...tus deshonestas manos me fatigan cuando pasan de la razón. (XIX, 222)

Sin embargo, el lenguaje de las manos de Calisto recibe la respuesta apropiada de parte del cuerpo de su amada pues le oímos exclamar lleno de emoción "Jamás querría, señora, que amaneciese, según la gloria y descanso que mi sentido recibe de la noble conversación de tus delicados miembros" (XIX, 223). El lector percibe y oye a los enamorados en comunión, no sólo a través del lenguaje articulado que sale de sus bocas, sino también por medio del lenguaje que expresan sus cuerpos, y que en definitiva contribuye a cargar de emoción la escena. De este modo ambos lenguajes se conjugan para conmover a cualquier receptor de los mismos. Como señala Kenneth Burke, "Pure persuasion involves the saying of something, for an extra-verbal advantage to be got by the saying, but because of a satisfaction intrinsic to the saying" ( $A$ Graminar 792-793). La presencia de los cuerpos en diálogo placentero se conjuga con la elección de un lenguaje afectivo y fuertemente sensual, y de este modo, Calisto-emisor consigue romper las barreras que parecían rodear a Melibea-receptora. 
En el mismo orden, también el lenguaje de las manos celestinescas tiene efectos sorprendentes en Pármeno. Si bien éste parecía en un principio firmemente resuelto a no ceder ante Celestina, la vieja lo convence y lo domina haciendo uso de su retórica envolvente al mismo tiempo que se acompaña de su poder táctil. No en vano ante la resistencia de Pármeno la escuchamos decir con gestos malévolos y desafiantes "¿A las verdades nos andamos? Pues espera que yo te tocaré donde te duela" (VII, 124). Anteriormente ya le había recordado sus oscuros orígenes y hasta sus "contactos" con él cuando era niño "Allégate a mi, ven acá, que mil azotes y puñadas te di en este mundo y otros tantos besos" (I, 67). Mientras escuchamos a Celestina la vemos mover sus manos y su cuerpo en ademán conciliador y protector para con Pármeno. Un poco antes le había amonestado y se había dirigido a éste con gestos recriminadores y de reprobación "Bien te oí, y no pienses que el oír con los otros exteriores sesos mi vejez haya perdido. Que no sólo lo que veo, oigo y conozco; más aún lo intríseco con los intelectuales ojos penetro. Has de saber..." (I, 65). De la implícita amenaza en sus palabras y gestos pasa Celestina otra vez al lenguaje lisonjero y cariñoso mientras la visualizamos queriendo acariciar el rostro y los hombros del indefenso criado. Por eso le dice "¡Neciuelo; loquito, angelico, perlica, simplecico! ¿Lobitos en tal gestico? LLégate acá, putico, que no sabes nada del mundo ni de sus deleites" (I, 65-66). Pármeno cae en las manos de Celestina, y ella sabe sacar el máximo provecho de su discurso halagador unido a sus gestos protectores y prometedores de placeres anhelados por el que a sí mismo se considera mozo.

Areúsa es otra de las sometidas a los poderes táctiles de Celestina. Cuando ésta la visita porque se la ha prometido a Pármeno como premio a su sumisión, aquélla asegura no sentirse en buenas condiciones físicas para pasar la noche con un hombre. Celestina consigue hacerle cambiar de opinión. Para ello emplea de nuevo su lenguaje envolvente al mismo tiempo que hace uso de su tacto. Levanta las ropas de la cama de Areúsa mientras ensalza su olor y su blancura y se acerca a la prostituta en plan cariñoso, de tal manera que Areúsa exclama "¡Paso, madre, no llegues. a mí, que me haces coxquillas y provócasme a reír y la risa acreciéntame el dolor!" (VII, 127). Al insistir Areúsa en su sufrimiento, Celestina propone "tentarla," como buena entendida en males femeninos, para calmar su malestar. Mientras palpa y toca ávidamente el cuerpo de la joven no cesa en alabar sus dones "No parece que hayas quince años. ¡Oh quien fuera hombre y tanta parte alcanzara de ti para gozar tal vista!" (VII, 127). Por último, concluye en términos de amonestación para Areúsa "Que no creas que en balde fuiste criada...Mira que es pecado fatigar y dar pena a los hombres, pudiéndolos remediar" (VII, 127). Cuando Celestina abandona la casa 
deja a Pármeno y a Areúsa entregados al lenguaje amoroso de sus cuerpos "que voyme sólo porque me haceis dentera con vuestro besar y retozar. Que aun el sabor en las encías me quedó; no lo perdí con las muelas" (VII, 132). Todo el lenguaje expresado corporalmente en las escenas amorosas añade dramatismo a la acción, como bien ha señalado Lida de Malkiel. Sin embargo disentimos con ella cuando asegura que "The undeniably spiritual quality of love in The Celestina... is in essence incompatible with obscenity" (Lida, 1961: 90). En nuestra opinión los gestos, posturas $y$ ademanes reforzados por el lenguaje verbal contribuyen en buena medida a que el receptor interprete como obscenos tanto los encuentros amorosos como muchos comentarios de Celestina.

Pero no todo es correspondencia entre ambos lenguajes: el corporal y el verbal. A menudo, el primero se manifiesta en determinadas formas de comportamiento expresadas en forma de gestos y posturas que enmascaran y contradicen la comunicación verbal. En este sentido, Julius Fast en Body Language señala:

Spoken language alone will not give us the full meaning of what a person is saying, nor for that matter will body language alone give us the full meaning. If we listen only to the words when someone is talking, we may get as much of a distorsion as we would if we listened only to the body language. (118)

Disimulación y simulacro derivan de los enunciados verbales humanos con determinados fines: uno de ellos es la manipulación y demostración de poder sobre los interlocutores, como ya hemos estudiado en la primera parte de nuestro ensayo. Otro es la tortura psíquica. Tanto Melibea como Celestina son buenos ejemplos del poder de sus lenguajes corporales. Estos enmascaran y contradicen sus discursos verbales de tal forma, que sadismo y masoquismo - como impulsos de negatividad y de muerte - se encuentran implícitos en varios momentos de su dialogar a lo largo del texto. Melibea es una reina de la simulación. Ya en el primer auto notamos que sus palabras "Pues aun más igual galardón te daré yo, si perseveras" (I, 46) contienen un deseo explícito de hacer sufrir a Calisto. En la primera entrevista con Celestina, sigue Melibea dispuesta a simular su verdadera pasión. La vemos haciendo grandes gestos por apartar a Celestina: ¡"Quítamela, Lucrecia, de delante, que me fino, que no me ha dejado gota de sangre en el cuerpo!" (IV, 95). Sin embargo, escuchamos más tarde de su propia boca lo que sus gestos encubren, al mismo tiempo que confiesa haber sufrido por ello "¿Por qué no fue también a las hembras concedido poder 
descubrir su congojoso y ardiente amor, como a los varones? Que ni Calisto viviera quejoso ni yo penada" $(X, 154)$.

En la segunda entrevista con Celestina, Melibea sigue fingiendo que no quiere ceder a Calisto: "Más agradable sería que rasgases mis carnes y sacases mi corazón, que no traer esas palabras aquí" $(X, 158)$, cuando su cara y su cuerpo dan muestras físicas de estar sintiendo lo contrario "¿Qué es de tu habla graciosa; qué es de tu color alegre? Abre tus ojos claros. ¡Lucrecia, Lucrecia, entra presto acá y verás amortecida a tu señora en mis manos!" $(X, 159)$. Finalmente cuando Melibea declara su deseo por Calisto reconoce experimentar un gran alivio, que los lectores y oyentes perciben no sólo a través de sus palabras sino también en los gestos de su cuerpo "Lo que tú tan abiertamente conoces, en vano trabajo por te lo encubrir ... Pospuesto todo el temor, has sacado de mi pecho lo que jamás a ti ni a otro pensé descubrir" $(X, 160)$. Lucrecia sin embargo no necesitaba de las palabras de Melibea para conocer sus sentimientos, ya que le replica:

Señora, mucho antes de agora tengo sentida tu llaga y callado tu deseo. Hame fuertemente dolido tu perdición. Cuanto más tú me querías encubrir y celar el fuego que te quemaba, tanto más sus llamas se manifestaban en la color de tu cara, en el poco sosiego del corazón, en el meneo de tus miembros, en comer sin gana, en el no dormir. Así que continuo se te caían, como de entre las manos, señales muy claras de pena. $(X, 161)$

El cuerpo, objeto de percepción, es el primero en delatarse, en llevar a cabo una comunicación sincera, a pesar de que las palabras lo pretendan encubrir, e incluso aun cuando éstas no se producen. Sempronio también insiste en ello al ver acercarse a Celestina:

[E]l ánimo es forzado descubrillo por estas exteriores señales, ¿Quién jamás te vido por la calle, abajada la cabeza, puestos los ojos en el suelo, y no mirar a ninguno como agora? ¿Quién te vido hablar entre dientes por las calles y venir aguijando, como quien va a ganar beneficio? Que desde que dio la una, te espero aquí y no he sentido mejor señal que tu tardanza. (V, 103)

Nosotros, receptores ávidos, ya la habíamos imaginado feliz y contenta lamentando no poder ir más de prisa en su atravesar la calle desde la casa de Melibea a la de Calisto ";Oh malditas haldas, prolijas y 
largas, cómo me estorbáis de llegar adonde han de reposar mis nuevas!" $(V, 103)$. El cuerpo de Celestina, en sus desplazamientos de un lugar a otro a lo largo del texto, es el mejor indicador de sus estados de ánimo: ya dubitativo "Ya veo su puerta. En mayores afrentas me he visto. ¡Esfuerza, esfuerza Celestina! ¡No desmayes!" (IV, 87); ya confiado y seguro "Nunca he tropezado como otras veces. Las piedras parece que se apartan y me hacen lugar que pase. $\mathrm{Ni}$ me estorban las haldas ni siento cansancio en el andar. Todos me saludan" (IV, 87).

El haldear de Celestina es visualizado en varias ocasiones por los receptores del texto. En primer lugar nos llega por boca de Sempronio "¿Qué espacio lleva la barbuda; menos sosiego traían sus pies a la venida!" (III, 79), anticipando ya, en parte, la animadversión que este criado siente por Celestina. Después de escuchar su soliloquio acompañado de su caminar, pausado en un principio y enérgico al final, la vemos llegar a casa de Melibea decidida a cumplir su misión, de modo que Lucrecia se pregunta "¿Quién es esta vieja que viene haldeando?" (IV, 88). Como señala Americo Castro en 'La Celestina' como contienda literaria (150), "sus vidas humanas saben unas de otras, se representan unas a otras en varias formas; no se afectan unas a otras sólo por lo que hacen, sino a través de cómo son vividas por las otras... de esta forma $L a$ Celestina inicia la técnica del perspectivismo literario." Nosotros, los receptores que escuchamos atentos la lectura del texto imaginamos a Celestina caminando, pero también visualizamos sus emociones y sus pasiones, cuando Sempronio, Lucrecia o la vieja misma nos trasmiten señales que provienen de sus cuerpos perceptibles. Gilman coincide en este punto con Castro y así afirma en la introducción (27) a la edición que estamos utilizando de Celestina:

Y no sólo la vemos; frecuentemente esos ojos interpretan para nosotros el significato sentimental de sus cambios de paso: júbilo triunfal, duda frente al peligro o precaución física cuando va maniobrando con su viejo cuerpo entre las piedras y los agujeros del pavimento medieval.

La espacialidad y la temporalidad que derivan de la existencia de los cuerpos, de su movilidad, de su expresión, en suma, de su lenguaje es otro de los logros de la obra de Fernando de Rojas. No cabe duda de que el lenguaje corporal interpretado por "las distintas vidas" de la obra contribuye a hacer de la misma "un híbrido" que intercambia y combina géneros diversos como la comedia, el drama, o la novela. De manera singular, el espacio y el tiempo vienen marcados por las distintas expresiones, gestos, posturas, y desplazamientos de los cuerpos. 
Escuchamos a Calisto afirmar después de su primera noche de amor "Gran reposo he tenido...Y no me maravillo que lo uno y lo otro se juntasen para cerrar los candados de mis ojos, pues trabajé con el cuerpo y persona y holgué con el espíritu y sentido la pasada noche" (XIII, 185); vemos a Elicia a través de las palabras de Sosia que la describe al verla pasar por la calle: "Llégate acá y verla has antes que trasponga. Mira aquella lutosa que se limpia las lágrimas de los ojos. Aquélla es Elicia, criada de Celestina y amiga de Sempronio" (XIV, 197). Sabemos de la desesperación de Elicia por las palabras de Areúsa "Dímelo, no te meses, no te rascuñes ni maltrates. ¿Es común de entrambas este mal? ¿Tócame a mí?" (XV, 199).

En definitiva, acordamos la importancia del cuerpo y las señales emitidas por el mismo cuando se trata de obtener el máximo de comunicación. Si como hemos asegurado anteriormente, para los teóricos de la fenomenología de la percepción el carácter social del lenguaje se manifiesta a través del cuerpo y sus gestos, una obra como Celestinn en la que la intersubjetividad es elemento indispensable, por ser prácticamente toda ella dialogada, Fernando de Rojas logra en la misma un efecto único: consigue que los diversos lenguajes, tanto los verbales como los corporales de las distintas "vidas" implicadas en el "proceso" se conviertan también en "signos" encarnados en las distintas voces que los emiten $y$, simultáneamente, queden inscritos en el "cuerpo" del texto.

La profusión del signo "cuerpo" y la textualización constante y obsesiva de sus cinco sentidos, presenta sin embargo una relación dialéctica en el texto de Rojas. Por un lado ensalza y destaca el cuerpo de manera extraordinaria, siguiendo así una tradición iniciada por Juan Ruiz en el Libro de Buen Amor. Por otro lado, lo victimiza, textualizándolo como causa de la perdición y el castigo de los distintos personajes en acción. De modo que disentimos con Octavio Paz cuando asegura que Celestina representa un momento de la historia literaria española en la que el binomio "cuerpo"/ "no cuerpo" mantiene un equilibrio armonioso, y nos recuerda que "no somos únicamente descendientes de Quevedo" (Paz, 1978: 23). Sin duda, Paz se refiere con esta afirmación a la institucionalización de la represión y negación del signo "cuerpo" en la mayor parte de la literatura del Siglo de Oro y pretende apuntar lo positivo de la profusión corporal en la obra de Rojas.

En nuestra opinión, Fernando de Rojas, situado entre el Arcipreste y Quevedo nos transmite en su obra el clamor angustiado del cuerpo, enfrentándose con la ideología dogmática que lo oprime. Al escribir en el Prólogo, apoyándose en Heráclito y Petrarca, que "bien afirmaremos ser todas las cosas criadas a manera de contienda" (42), 
Rojas nos da la respuesta más convincente acerca de su terrible negación del cuerpo, después de haberlo afirmado tanto. Aun cuando Celestina consigue "tener en sus manos" a los demás protagonistas de la obra, ella misma termina muriendo a manos de Sempronio:

PARM.-¡Dale, dale, acábale, pues comenzaste! !Que nos sentirán! !Muera, muera; de los enemigos los menos!

CEL.- ¡Confesión!

ELIC. - ¡Oh crueles enemigos, en mal poder os veáis! ¡Y para quién tuvisteis manos! !Muerta es mi madre y mi bien todo!

(XIII, 184)

Escuchamos los gritos ahogados de Celestina a la vez que vemos su cuerpo, que habia sido tan vitalista, ya muerto. Lo mismo sucede con los criados asesinos. Desde Sosia nos llega el relato escalofriante de su visión de Sempronio y Pármeno acabados "que si los vieras, quebraras el corazón de dolor! El uno llevaba todos los sesos de la cabeza de fuera ... el otro quebrados entrambos brazos y la cara magullada ... Y así casi muertos les cortaron las cabezas" (XIII, 187). Cuerpos rotos, escindidos, fragmentados, cuando antes habían estado llenos de vida. Con Calisto y Melibea presenciamos visiones semejantes. Dice Tristán "Cayó mi señor Calisto del escala y es muerto. Su cabeza está en tres partes" (XIX, 225) y Pleberio se lamenta "porque no llore yo solo la pérdida dolorida de entrambos, ves allí a la que tú pariste y yo engendré, hecha pedazos" (XXI, 232). Del triunfo absoluto del cuerpo se pasa a la aniquilación del mismo.

Esto no debe extrañarnos si, como han demostrado Castro, Lida de Malkiel y Gilman, la situación marginal y conflictiva de Rojas con respecto a la sociedad española de la época fue realmente determinante en lo que se refiere a la elaboración de la Tragicomedia. Las decisivas premoniciones del Prólogo "¿Qué mayor lid, qué mayor conquista ni guerra que engendrar en su cuerpo quien coma sus entrañas?" (41) se cumplen a lo largo del texto. Todos los personajes que mueren son víctimas de las pasiones, enemistades, envidias, que ellos mismos habian generado y cultivado en sus propios cuerpos. Es por eso que el texto destroza, fragmenta, y nos presenta el horror de unos cuerpos que habían estado en diálogo y en movimiento constantes. El nihilismo de la obra y su poder corrosivo y violento se mantienen todavía vivos quinientos años después de su publicación porque excéntrico y periférico, Rojas escapa con fuerza centrífuga única al despotismo de una máquina administrativa centrípeta. "El 'cuento de horror' que le ha hecho ver y vivir a él la 
sociedad, se convertirá en esa admirable 'historia de horror' que es, a fin de cuentas, Celestina" (Goytisolo 17).

Como conclusión, la dualidad cuerpo/mente - propuesta como componente indivisible y exclusivo del sujeto en la época en la que se escribió la Tragicomedia - es ampliada de modo sorprendente por parte de Fernando de Rojas al enfatizar el primero como un producto cultural, es decir, como superficie o espacio en el que se inscriben anotaciones no sólo de género sexual, sino también políticas, sociológicas e históricas. La articulación y posterior desarticulación existente entre lo biológico y lo psicológico, entre el interior y el exterior del cuerpo físico, propone una visión muy avanzada para la época en la que se escribió la obra: tanto las dimensiones psíquicas como sociales de los cuerpos de esas vidas "en proceso" quedan maravillosamente inscritas en sus páginas, al tener en cuenta las relaciones indisolubles entre los gestos, las posturas, los semblantes y los movimientos corporales en la constitución y posterior proyección de representaciones psíquicas y emocionales de los distintos personajes en acción. El lenguaje de sus cuerpos es lo suficientemente persuasivo como para mantenerse vivo, incluso quinientos años después de haber sido inscrito en el espacio textual por Fernando de Rojas. De ahí que Celestina siga vigente y prosiga su clandestina a la vez que convincente labor a la captura del espíritu y del cuerpo del receptor. Las "señales" que desprenden los cuerpos de las "vidas" en "proceso" están destinadas a conmoverlo, inquietarlo, trastornarlo $y$, en última instancia, a contaminarlo.
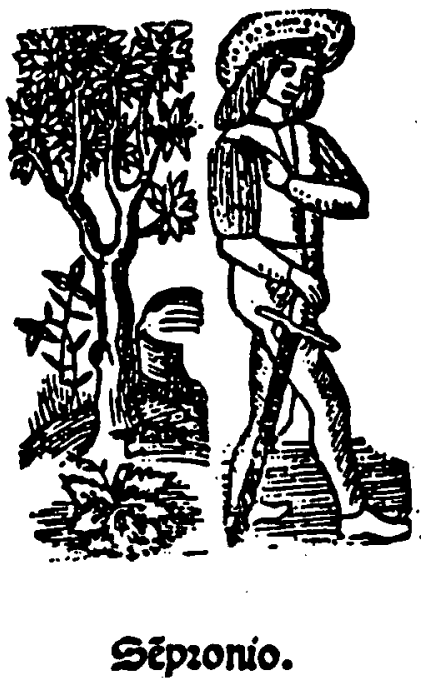


\section{OBRAS CITADAS}

BURKE, Kenneth. A Grammar of Motives and a Rhetoric of Motives. Cleveland: World Publishing Company, 1962.

CASTRO, Américo. 'La Celestina' como contienda literaria. Madrid: Revista de Occidente, 1965.

FAST, Julius. Body Language. New York: M. Evans, 1970.

FEYEREISEN, Pierre, y DE LANNOY, Jacques Dominique. Gestures and Speech: Psychological Investigations. Cambridge: Cambridge UP, 1991.

GILMAN, Stephen. La España de Fernando de Rojas: panorama intelectual y social de 'La Celestina'. Madrid: Taurus, 1978.

GOYTISOLO, Juan. Disidencins. Barcelona: Seix Barral, 1978.

LIDA DE MALKIEL, María Rosa. Two Spanish Masterpieces. The 'Book of Good Love' and 'The Celestina'. Urbana: The University of Illinois Press, 1961.

MERLEAU-PONTY, Maurice. La phénomenologie de la perception. Paris: Gallimard, 1945.

PAZ, Octavio. Conjunciones y disyunciones. México: Joaquín Mortiz, 1991. ROJAS, Fernando de. La Celestina, ed. D. S. Severin. Madrid: Alianza Editorial, 1969.

Cover art. Madrid: Alba, 1986

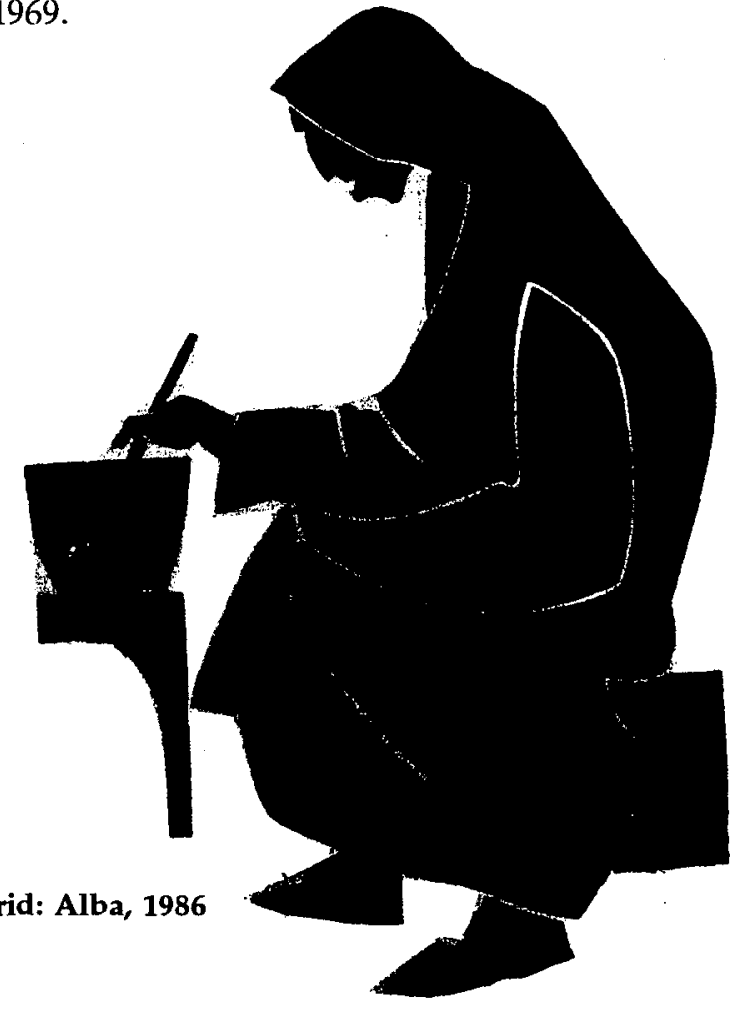

